\title{
Retrieving high-resolution surface solar radiation with cloud parameters derived by combining MODIS and MTSAT data
}

\author{
Wenjun Tang ${ }^{1,2}$, Jun Qin ${ }^{1}$, Kun Yang ${ }^{1,2}$, Shaomin Liu $^{3}$, Ning Lu ${ }^{4}$, and Xiaolei Niu ${ }^{1}$ \\ ${ }^{1}$ Key Laboratory of Tibetan Environment Changes and Land Surface Processes, Institute of Tibetan Plateau Research, \\ Chinese Academy of Sciences, Beijing 100101, China \\ ${ }^{2}$ CAS Center for Excellence in Tibetan Plateau Earth Sciences, Chinese Academy of Sciences, Beijing 100101, China \\ ${ }^{3}$ State Key Laboratory of Remote Sensing Science, School of Geography, Beijing Normal University, Beijing 100875, China \\ ${ }^{4}$ State Key Laboratory of Resources and Environmental Information System, Institute of Geographic Sciences and Natural \\ Resources Research, Chinese Academy of Sciences, Beijing 100101, China \\ Correspondence to: Wenjun Tang (tangwj@itpcas.ac.cn)
}

Received: 9 November 2015 - Published in Atmos. Chem. Phys. Discuss.: 15 December 2015

Revised: 17 February 2016 - Accepted: 18 February 2016 - Published: 2 March 2016

\begin{abstract}
Cloud parameters (cloud mask, effective particle radius, and liquid/ice water path) are the important inputs in estimating surface solar radiation (SSR). These parameters can be derived from MODIS with high accuracy, but their temporal resolution is too low to obtain high-temporalresolution SSR retrievals. In order to obtain hourly cloud parameters, an artificial neural network (ANN) is applied in this study to directly construct a functional relationship between MODIS cloud products and Multifunctional Transport Satellite (MTSAT) geostationary satellite signals. In addition, an efficient parameterization model for SSR retrieval is introduced and, when driven with MODIS atmospheric and land products, its root mean square error (RMSE) is about $100 \mathrm{~W} \mathrm{~m}^{-2}$ for 44 Baseline Surface Radiation Network (BSRN) stations. Once the estimated cloud parameters and other information (such as aerosol, precipitable water, ozone) are input to the model, we can derive SSR at high spatiotemporal resolution. The retrieved SSR is first evaluated against hourly radiation data at three experimental stations in the Haihe River basin of China. The mean bias error (MBE) and RMSE in hourly SSR estimate are $12.0 \mathrm{~W} \mathrm{~m}^{-2}$ (or $3.5 \%$ ) and $98.5 \mathrm{~W} \mathrm{~m}^{-2}$ (or $28.9 \%$ ), respectively. The retrieved SSR is also evaluated against daily radiation data at 90 China Meteorological Administration (CMA) stations. The MBEs are $9.8 \mathrm{~W} \mathrm{~m}^{-2}$ (or $5.4 \%$ ); the RMSEs in daily and monthly mean SSR estimates are $34.2 \mathrm{~W} \mathrm{~m}^{-2}$ (or $19.1 \%$ ) and $22.1 \mathrm{~W} \mathrm{~m}^{-2}$ (or $12.3 \%$ ), respectively. The accuracy is comparable to or even higher than two other radiation products (GLASS and
\end{abstract}

ISCCP-FD), and the present method is more computationally efficient and can produce hourly SSR data at a spatial resolution of $5 \mathrm{~km}$.

\section{Introduction}

Surface solar radiation (SSR), as a component of the surface radiation budget, is the primary source of energy for the Earth's system. It controls both water and energy exchanges on the land surfaces and is thus a major forcing for land surface models, hydrological models, and ecological models (Xue et al., 2013; Huang et al., 2016). SSR is also essential for many applications such as determination of the site of solar power stations and design of heating systems (Berbery et al., 1999; Oliver and Jackson, 2001; Roebeling et al., 2004; Mondol et al., 2008; Benghanem and Mellit, 2010). However, in situ measurements of SSR are sparse, which are not adequate to represent regional characteristics of SSR, due to high spatial variability in SSR, especially in mountain regions.

Satellites can be utilized to retrieve spatially continuous SSR over a wide geographical extent. Currently, there are several global satellite SSR products, such as the Global Energy and Water cycle Experiment Surface Radiation Budget (GEWEX-SRB; Stackhouse et al., et al., 2004) and the International Satellite Cloud Climatology Project Flux Data (ISCCP-FD; Zhang et al., 2004). But their spatial resolutions 
( $>100 \mathrm{~km}$ ) are too coarse to satisfactorily meet the requirements of land surface processes studies and practical applications. Moreover, their accuracy needs further improvements. As indicated by Yang et al. (2008), the SSR of GEWEX-SRB and ISCCP-FD have large discrepancies in highly variable terrain in the Tibetan Plateau. Wu et al. (2011) evaluated the monthly mean SSR of GEWEX-SRB over China and found that the SSR was generally overestimated over eastern China but occasionally underestimated over western China. Therefore, it is necessary to develop new methods that can produce high-accuracy and high-resolution SSR products.

Numerous methods have been developed to retrieve SSR from satellite signals. These methods can be roughly divided into three categories. The first consists of look-up table methods that use satellite signals to match a pre-established radiative-transfer database (Pinker et al., 2003; Liang et al., 2006; Mueller et al., 2009; Lu et al., 2010; Huang et al., 2011; Ma and Pinker, 2012). These methods are not computationally economical, and most of them only use visible channel data. The second consists of parameterization methods that directly calculate SSR by a parameterization model, with inputs of cloud, aerosol and other atmospheric and surface variables (Zhang et al., 2004; Halthore et al., 2005; Wang and Pinker, 2009; Kim and Ramanathan, 2008; Huang et al., 2012; Sun et al., 2012). Some inputs (e.g., cloud parameters) of these methods change rapidly, but it is hard to get them with high temporal resolution. The third consists of statistical methods that directly link satellite-observed signals to SSR measurements at regional scales (Lu et al., 2011). The disadvantage of these methods is their limited generalization. In addition, combination of the above methods is also widely adopted by many researchers (e.g., Hammer et al., 2003; Rigollier et al., 2004; Posselt et al., 2012; Wang et al., 2011, 2014; Tanahashi et al., 2001; Kawai and Kawamura, 2005; Yeom et al., 2008; Yeom and Han, 2010). These combined methods firstly calculate clear-sky SSR by means of a look-up table method or a parameterization method, and then the cloud index or cloud attenuation coefficient derived from satellite data is used to calculate all-sky SSR. Their applicability needs further tests at global scale.

Currently, both polar-orbit and geostationary satellites can be used to retrieve the SSR, with different merits and disadvantages. Sensors onboard polar-orbit satellites generally have higher spectral resolutions than geostationary satellites. For example, the Moderate Resolution Imaging Spectroradiometer (MODIS) onboard the Terra and Aqua platforms has 36 spectral bands, but the Multifunctional Transport Satellite (MTSAT) and Geostationary Operational Environmental Satellites (GOES) have only 5 spectral bands. Sensors with high spectral resolution have a great advantage in retrieving cloud properties (Huang et al., 2006). For example, MODIS can provide cloud property data with high accuracy, which are used in many studies for SSR estimation (Wang et al., 2009; Huang et al., 2011; Qin et al., 2015). However, their temporal resolutions are too low to capture the diurnal
Table 1. Characteristics of MTSAT bands used in this study.

\begin{tabular}{lrr}
\hline Channel & Band wavelength $(\mu \mathrm{m})$ & Resolution at nadir $(\mathrm{km})$ \\
\hline VIS & $0.55-0.90$ & $1.0 \times 1.0$ \\
IR-1 & $10.3-11.3$ & $4.0 \times 4.0$ \\
IR-2 & $11.5-12.5$ & $4.0 \times 4.0$ \\
IR-3 & $6.5-7.0$ & $4.0 \times 4.0$ \\
IR-4 & $3.5-4.0$ & $4.0 \times 4.0$ \\
\hline
\end{tabular}

cycle. By contrast, geostationary satellites can provide continuous observations with high temporal resolution, and thus can capture the diurnal cycle of sky conditions at regional scales. But it is difficult to directly derive cloud properties based on geostationary satellites due to their low spectral resolution (King et al., 1997; Huang et al., 2005; Minnis et al., 2007). It is well known that the largest uncertainties in satellite retrieval of SSR are attributed to the inadequate information on cloud properties. Combination of polar-orbit and geostationary satellites may provide an opportunity to derive the cloud properties at high temporal resolution.

This paper presents a new method to quickly estimate SSR by combining signals of polar-orbit and geostationary satellites. This method includes two steps. The first step is to estimate hourly cloud parameters by combining high-accuracy cloud products of MODIS and high-temporal-resolution topof-the-atmosphere (TOA) radiance data of all MTSAT channels. The second step is to use the cloud information and other auxiliary information in an efficient parameterization model to retrieve SSR at a high spatiotemporal resolution. The paper is organized as follows. The data used are introduced in Sect. 2. The SSR retrieval scheme is presented in Sect. 3. Section 4 presents the validation results and discussions. Finally, conclusions and remarks are given in Sect. 5.

\section{Data}

\subsection{MTSAT data}

The MTSAT (which includes MTSAT-1R and MTSAT-2) data of the Japan Meteorological Agency (JMA) are used in this study. MTSAT-1R, launched on 26 February 2005, is positioned at $140^{\circ} \mathrm{E}$ above the Equator, and MTSAT-2, launched on 18 February 2006, is positioned at $145^{\circ} \mathrm{E}$ above the Equator. As the next generation of satellite series, they succeed the Geostationary Meteorological Satellite (GMS) series and take over the role of observing eastern Asia and the western Pacific. The imager onboard MTSAT scans the Earth every $30 \mathrm{~min}$ and provides images in five channels (see Table 1). The spatial resolution of MTSAT data at nadir is $1 \mathrm{~km}$ for the visible sensor, and $4 \mathrm{~km}$ for all the other infrared sensors. The visible and infrared data were resampled to a spatial resolution of $5 \mathrm{~km}$ by Kochi University, and all these five-channel data are used in this study to retrieve SSR. 


\subsection{MODIS products}

The MODIS level-2 products (version 5.1) are used in this study. These MODIS products contains cloud products (MOD06, MYD06), aerosol products (MOD04, MYD04), atmospheric profiles products (MOD07, MYD07), and albedo products (MCD43C3), where MOD denotes data collected from the Terra platform, MYD indicates data collected from Aqua platform, and MCD means combined product derived from both Terra and Aqua platforms (Schaaf et al., 2002; King et al., 2003). The spatial resolutions of the aerosol products (MOD04, MYD04), atmospheric profiles products (MOD07, MYD07), and albedo products (MCD43C3) are $5 \mathrm{~km}$, whereas the spatial resolution of cloud products is $1 \mathrm{~km}$. Thus we resample the cloud products to a spatial resolution of $5 \mathrm{~km}$. The temporal resolution of atmosphere products is generally two daytime observations every day, while that of MCD43C 3 is 16 days.

These products are used for two purposes. One is to evaluate a new SSR retrieval algorithm developed by the authors (Qin et al., 2015), which is driven by MODIS atmospheric and land products. The inputs of this algorithm are MODIS products of precipitable water, aerosol loading, ozone thickness, surface pressure, effective particle radius of water/ice cloud, liquid/ice water path, cloud fraction, and ground surface albedo. The other is to build mathematical relationships between MODIS cloud products (effective particle radius and liquid/ice water path) and MTSAT signals through ANN training, and then the cloud properties are estimated from MTSAT signals by this ANN model. To reduce the uncertainty of the ANN model, we only select high-quality MODIS data for the training.

\subsection{SSR measurement data}

Three types of surface radiation observation data are used to validate SSR retrievals in this study. The first one is the ground measurements data collected at 44 Baseline Surface Radiation Network (BSRN) stations located in contrasting climatic zones (see the red cross marks in Fig. 1). Radiation observations at BSRN are conducted with instruments of the highest available quality and are recognized as the most reliable data. Their temporal resolutions are 1 or $3 \mathrm{~min}$. The measured SSR are averaged over $1 \mathrm{~h}$ centered on the satellite overpass. The second one is the in situ data collected at three experimental stations located in Haihe River basin, China. Figure 1 shows the spatial distribution of the experimental stations, which are marked by the blue cross symbols, and the basic information on the three stations are given in Table 2 . The radiation data were sampled at every 1 or $2 \mathrm{~s}$ and the average values of each 10 or $30 \mathrm{~min}$ were recorded. Detailed information about the observations is available in Liu et al. (2013). The third one is the daily SSR data at China Meteorological Administration (CMA) radiation stations. Figure 1 shows the geographical distribution of these radiation

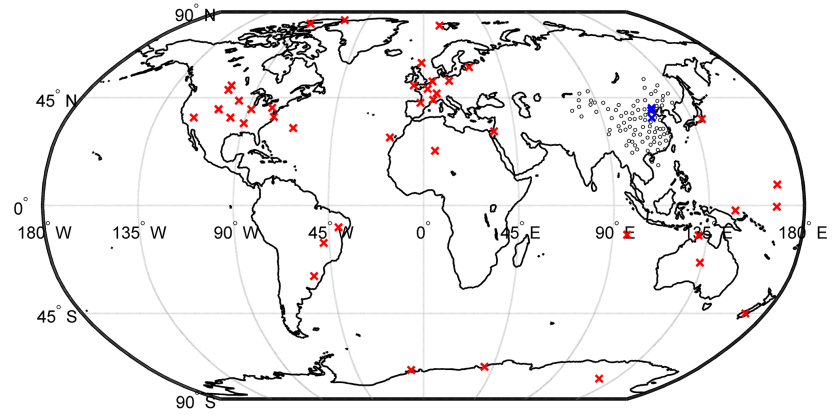

Figure 1. Spatial distribution of ground stations used for SSR retrieval validation. The red cross marks illustrate the 44 BSRN stations, the blue cross marks denote three experimental stations over the Haihe River basin in China, and the circle marks represent the 90 CMA radiation stations.

Table 2. The basic information of three experimental stations over the Haihe River basin.

\begin{tabular}{lrrrr}
\hline $\begin{array}{l}\text { Station } \\
\text { name }\end{array}$ & $\begin{array}{r}\text { Latitude } \\
\left({ }^{\circ} \mathrm{N}\right)\end{array}$ & $\begin{array}{r}\text { Longitude } \\
\left({ }^{\circ} \mathrm{E}\right)\end{array}$ & $\begin{array}{r}\text { Altitude } \\
(\mathrm{m})\end{array}$ & $\begin{array}{r}\text { Instrument } \\
\text { height }(\mathrm{m})\end{array}$ \\
\hline Miyun & 40.6 & 117.3 & 350 & 30.8 \\
Daxing & 39.6 & 116.4 & 20 & 28.0 \\
Guantao & 36.5 & 115.1 & 30 & 15.7 \\
\hline
\end{tabular}

stations denoted by circles throughout China. The elevations of these stations vary from 1 to $4507 \mathrm{~m}$. A set of qualitycheck procedures have been applied to these data (Tang et al., 2010).

\section{SSR retrieval scheme}

The SSR retrieval scheme includes three key steps, as presented in Fig. 2. First, the clear-sky and cloudy conditions of the MTSAT data are flagged by cloud detection in the image preprocessing procedure (Sect. 3.1), and the cloudy pixels are divided into water cloud and ice cloud. Second, cloud parameters (effective particle radius and liquid/ice water path) are derived by ANN models (Sect. 3.2) built by all MTSAT channels signals and the MODIS level-2 cloud products. Third, the hourly SSR is estimated by a physical retrieval algorithm (Sect. 3.3), given the above derived cloud parameters and other inputs. Daily SSR values are obtained by integrating hourly SSR values. The following three subsections describe the details of each step.

\subsection{Cloud detection}

Because of limitations of traditional cloud detection methods (e.g., threshold approaches and statistical approaches) (Liu et al., 2009), an ANN method is trained with the LevenbergMarquardt optimization algorithm to detect clouds. Similar to MODIS cloud mask, three classes (water cloud, ice cloud, 


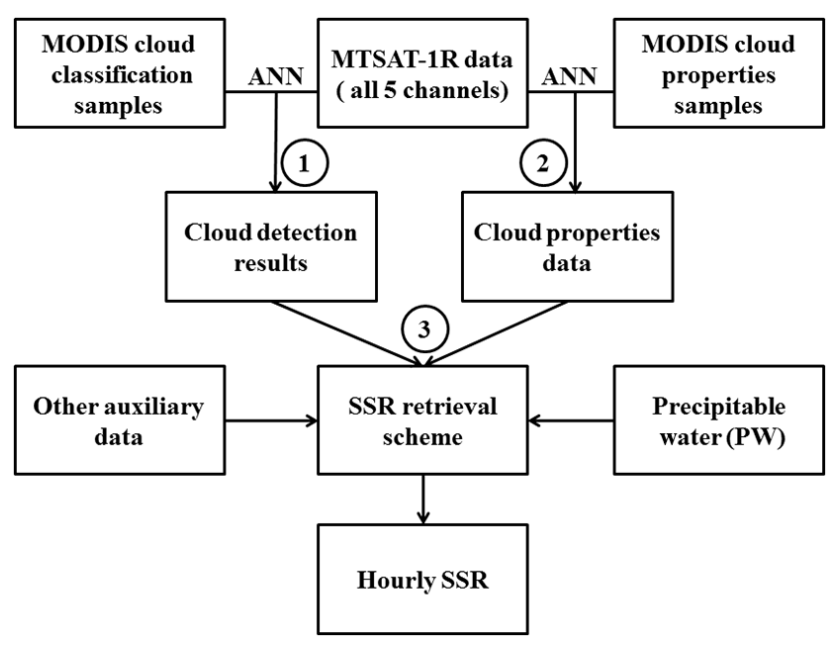

Figure 2. Flowchart of the SSR retrieval algorithm.

and clear land or sea) are defined. The ANN contains three layers: an input layer, an output layer, and one hidden layer between them. The input layer has nine parameters, which are five MTSAT channel signals, information of three angles (the cosines of satellite viewing zenith angle, solar zenith angle, and the relative azimuth angle between the sun and the satellite), and pixel's elevation. The hidden layer contains 20 neurons with a hyperbolic tangent sigmoid transfer function as the transfer function. In the output layer, three neurons with linear transfer function are utilized to denote the cloud detection results.

In the training, we select high-quality MODIS cloud mask data as the "truth" of the output, and the MTSAT signals as input. To enhance the possibility of distinguishing clouds from snow, we also randomly choose clear-sky pixels above snow surface and cloudy-sky pixels above the snow surface through visual identification. Finally, the trained ANN is used to detect clouds, and the result is one of clear sky, water cloud, and ice cloud.

One may question whether the trained ANN may lose representativeness for cases where solar zenith angles are large (e.g., the hours around sunrise and sunset), because the overpass times of Terra-MODIS and Aqua-MODIS roughly are 10:30 and 13:30 local time, around which the solar zenith angles are relatively small. To alleviate this issue, a large number of data points are selected in this study to train the ANN. These data points cover most of China and span all four seasons. We have checked the training data and found that the values of solar zenith angle vary from about 7.1 to $78.3^{\circ}$. This range of solar zenith angles is sufficiently wide except for extreme cases such as the hours around sunrise and sunset, but the value of SSR is very small in the extreme cases. Also, it should be noted that the angle information is not the determining factor in cloud detection.

\subsection{Cloud parameter estimation}

Similar to Sect. 3.1, another ANN model is used to estimate cloud parameters (effective particle radius and liquid/ice water path) from MTSAT image. Again, the ANN model is trained with high-quality MODIS cloud products as "truth" of the output and MTSAT signals as input. The MODIS cloud products are randomly selected and split into two parts: one for training and another for independent validation. Comparison between the two parts indicates that the trained ANNs behave similarly to each other. To improve the generalization of the ANN model, we use all the data to train the ANN.

Figures. 3 and 4 show the cloud parameter (effective particle radius and liquid/ ice water path) comparisons between the MODIS "true values" and the estimated ones by ANNs for water cloud and ice cloud, respectively, after all the data are used to train the ANN. It can be seen that the estimated effective particle radius for both water cloud and ice cloud are generally comparable to the observed ones, and their correlation coefficients are both greater than 0.60 . The estimated liquid/ice water path for both water cloud and ice cloud are generally consistent with the observed ones, and their correlation coefficients are both greater than 0.70 . The performance of the trained ANNs for both water cloud and ice cloud at other pixels, which are not used to build the ANNs, is similar to that of the ANNs in Figs. 3 and 4 (not shown here). Therefore, the built ANNs can catch the functional relationships between the MODIS cloud parameters and MTSAT signals. Based on the ANNs, the cloud parameters can be efficiently derived from MTSAT data for the estimation of high-spatiotemporal-resolution SSR.

To further investigate the effect of errors in cloud parameters estimates on the accuracy of the SSR retrieval algorithm, a sensitivity test of the SSR retrieval algorithm to cloud parameters (effective particle radius and liquid/ice water path) is presented in Fig. 5. The condition used for the sensitivity test is specified as a midlatitude atmosphere with a solar zenith angle of $60^{\circ}$, surface elevation of $0.0 \mathrm{~km}$, precipitable water of $0.14 \mathrm{~cm}$, total zone amount of $0.25 \mathrm{~cm}$, surface albedo of 0.2, and an Ångström turbidity coefficient of 0.1 . We estimated the sensitivity of SSR retrieval to estimation errors in both liquid/ice water path and effective particle radius. As shown in Figs. 3 and 4, the estimated mean effective particle radius within 1 standard deviation $(1 \sigma)$ correspond to the ranges of about $8-12$ and $22-30 \mu \mathrm{m}$ for water cloud and ice cloud, which would lead to SSR changing by about 25 and $15 \mathrm{~W} \mathrm{~m}^{-2}$ as seen from Fig. 5, respectively. The estimated mean cloud liquid/ice water path within $1 \sigma$ corresponds to the ranges of about $45-185$ and $80-240 \mathrm{~g} \mathrm{~m}^{-2}$, which would lead to SSR changing by about 154 and $172 \mathrm{~W} \mathrm{~m}^{-2}$, respectively. Obviously, errors in SSR caused by the cloud liquid/ice water path estimation errors are much greater than the ones caused by cloud effective particle estimation errors. 

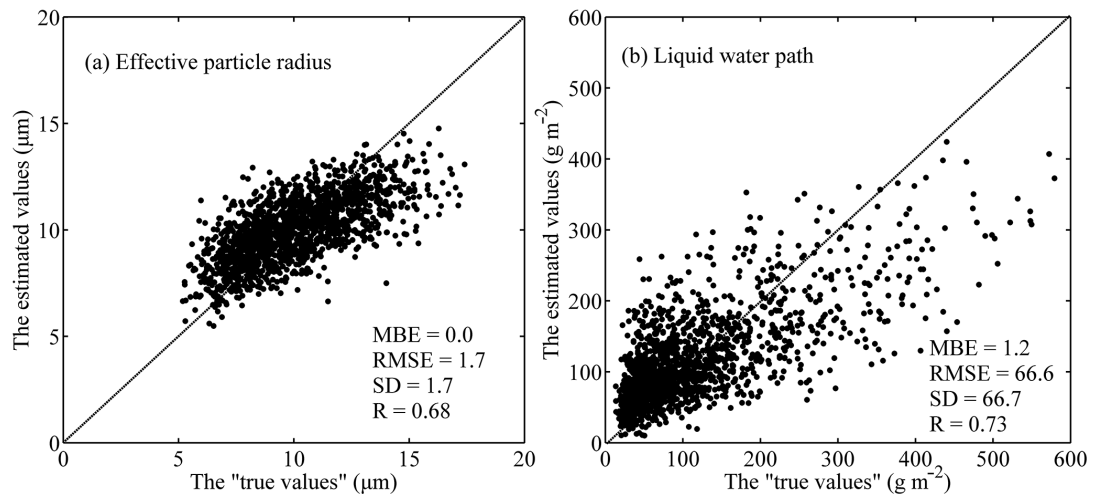

Figure 3. Comparisons of water cloud parameters between the MODIS "true values" and the estimated ones by ANN for (a) effective particle radius and (b) liquid water path.
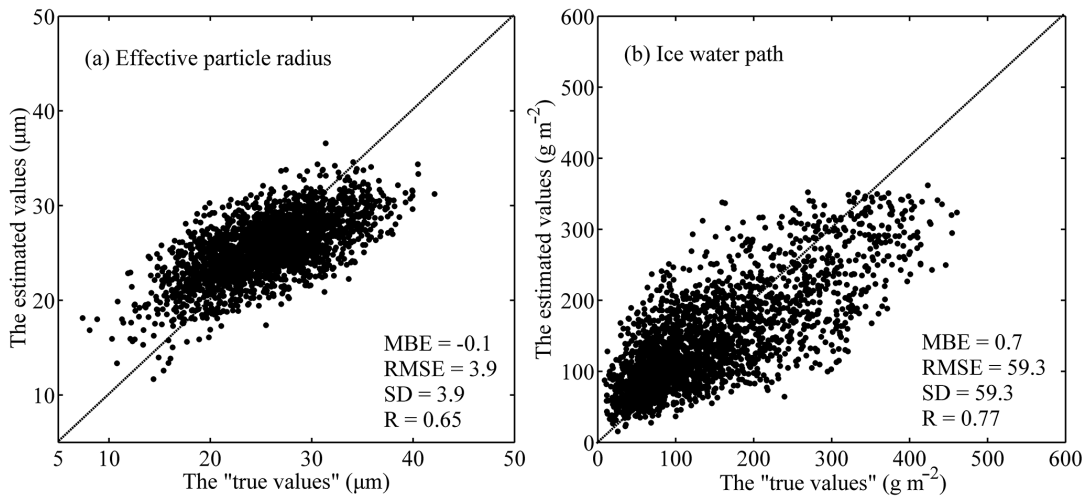

Figure 4. Same as Fig. 3 but for ice cloud.

\subsection{SSR retrieval algorithm}

The SSR retrieval algorithm used in this study is developed by Qin et al. (2015). This algorithm is mainly based on the cloud parameterization developed by Chou et al. (1999) and a clear-sky broadband radiative transfer model developed by Yang et al. (2006). A detailed description of cloud parameterization and the SSR parameterization is presented in Appendix $\mathrm{A} 1$ and $\mathrm{A} 2$, respectively.

In order to estimate the SSR, the retrieval algorithm needs to input cloud parameters, surface elevation, the precipitable water (PW), the thickness of ozone layer, the Ångström turbidity coefficient, and surface albedo. Qin et al. (2015) drove the algorithm with MODIS level-2 atmospheric and land products and validated the instantaneous SSR at nine stations. The mean root mean square error (RMSE) is about $100 \mathrm{~W} \mathrm{~m}^{-2}$. To further test the performance of the algorithm globally, we validated the instantaneous SSR estimated with MODIS products at 44 BSRN stations in 2009. Figure 6 presents validation results. The mean RMSEs for Terra and Aqua are about 101 and $106 \mathrm{~W} \mathrm{~m}^{-2}$, which may indicate that this algorithm can effectively retrieve SSR based on MODIS

products globally. Therefore, we may expect to apply the algorithm on the geostationary satellite.

The key of applying the SSR retrieval algorithm on geostationary satellite is the acquisition of input parameters. The cloud parameters can be derived efficiently by the ANNs in Sect. 3.2. The influence of the PW on the SSR is significant for the cloud-free conditions. Therefore, the PW here is derived by the split-window algorithm of Chesters et al. (1987) under cloud-free conditions as adopted by Tanahashi et al. (2001) and Lu et al. (2010). However, the PW for cloudy conditions is set at $2.9 \mathrm{~g} \mathrm{~cm}^{-2}$, as defined in the standard atmospheric profile of the mid-latitude summer model, since the cloud effects on the SSR are dominant. The Ångström turbidity coefficient is produced by the GADS (Global Aerosol Data Set 2.2a; see Koepke et al., 1997; Hess et al., 1998) model. The thickness of ozone layer is obtained from TOMS (Total Ozone Mapping Spectrometer) zonal means provided by the NASA/GSFC Ozone Processing Team (see https://ozoneaq.gsfc.nasa.gov/data/toms/). The surface elevation data are from the near-global elevation model Shuttle Radar Topography Mission (SRTM) 30 data set and have been averaged to the $0.05^{\circ}$ latitude-longitude 

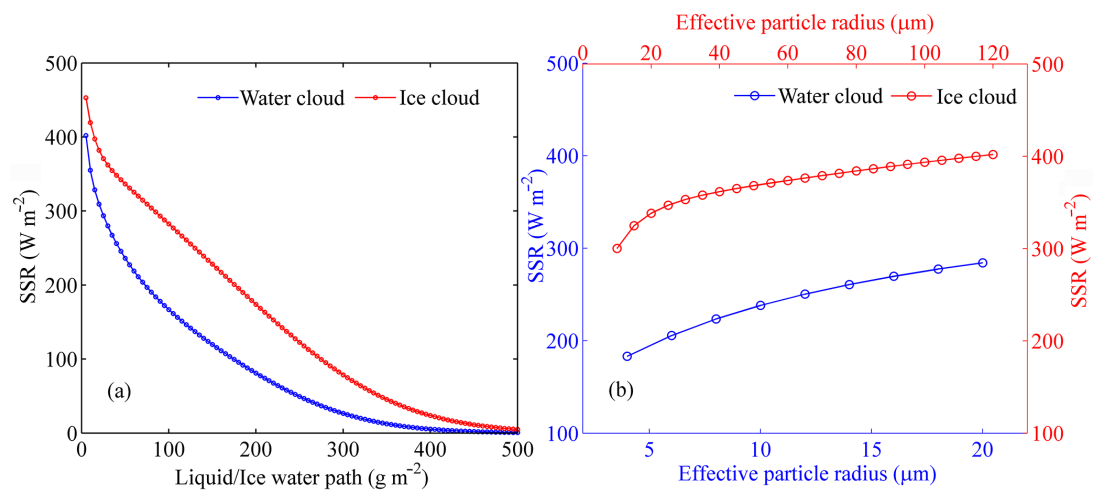

Figure 5. (a) Sensitivity of SSR to cloud liquid/ice water path, given the effective particle radius for water cloud and ice cloud of 12 and $30 \mu \mathrm{m}$, respectively. (b) Sensitivity of SSR to cloud effective particle radius for water cloud and ice cloud, given liquid/ice water path of $80 \mathrm{~g} \mathrm{~m}^{-2}$.
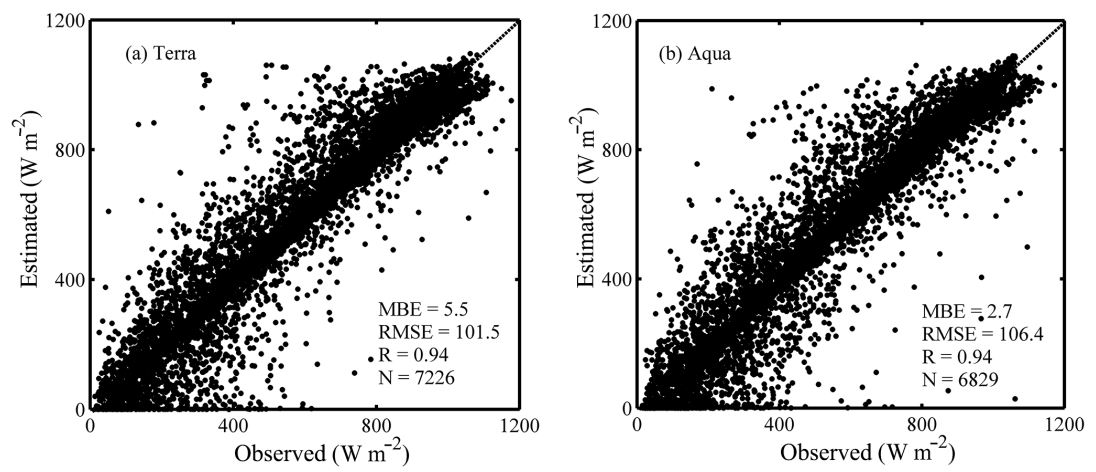

Figure 6. Validation of instantaneous SSR estimated with the MODIS atmospheric and land products against the observed ones at 44 BSRN stations in 2009 for (a) Terra and (b) Aqua platforms. Units of MBE and RMSE are W m ${ }^{-2}$.

grids of the MTSAT imagery. The surface albedo data are from the MODIS MCD43A3 16-day albedo.

\section{Results and discussions}

As mentioned above, SSR measurements at three experimental stations over the Haihe River basin and 90 CMA radiation stations in 2009 are used to evaluate the accuracy of the hourly, daily, and monthly SSR retrieval from collocated satellite pixels, respectively. The performance of the SSR estimate is evaluated using three metrics: mean bias error (MBE, in $\mathrm{W} \mathrm{m}^{-2}$ ), RMSE, (in $\mathrm{W} \mathrm{m}^{-2}$ ), and correlation coefficient $(R)$.

\subsection{Validation of hourly SSR in the Haihe River basin}

Pinker et al. (2003) pointed out that an hourly interval is suitable for evaluating satellite instantaneous SSR retrievals due to the dependence on the average speed of cloud movement. Furthermore, Deneke et al. (2009) demonstrated that the observed SSR averaging over a period of $40-80 \mathrm{~min}$ is optimal for a comparison with satellite retrievals. Therefore, here we adopt hourly SSR observations, centered on the time of the satellite overpass on the hour, to evaluate the satellitederived hourly values. Figure $7 \mathrm{a}-\mathrm{c}$ show the validation results of the hourly SSR estimates in 2009 at the three experimental stations (Miyun, Daxing, and Guantao) in Haihe River basin. The average RMSE on an hourly timescale for these three stations is $98.5 \mathrm{~W} \mathrm{~m}^{-2}(28.9 \%)$ and the corresponding MBE is $12.0 \mathrm{~W} \mathrm{~m}^{-2}(3.5 \%)$. The overall positive MBE indicates overestimation of the hourly SSR retrievals with MTSAT data at the three stations. The lack of threedimensional radiative effects in the SSR retrieval algorithm and the appearance of broken clouds are the potential reasons for the hourly SSR bias (Deneke et al., 2008). Another reason for the discrepancies may be attributed to the different amounts of cloud in the different illumination and viewing paths when comparing the satellite retrievals with the ground measurements (Liang et al., 2006). In addition, it might be caused by the retrieval algorithm error.

In other words, although the retrievals in Haihe River basin have slight biases toward overestimating the hourly SSR values, the results still indicate acceptable agreement 

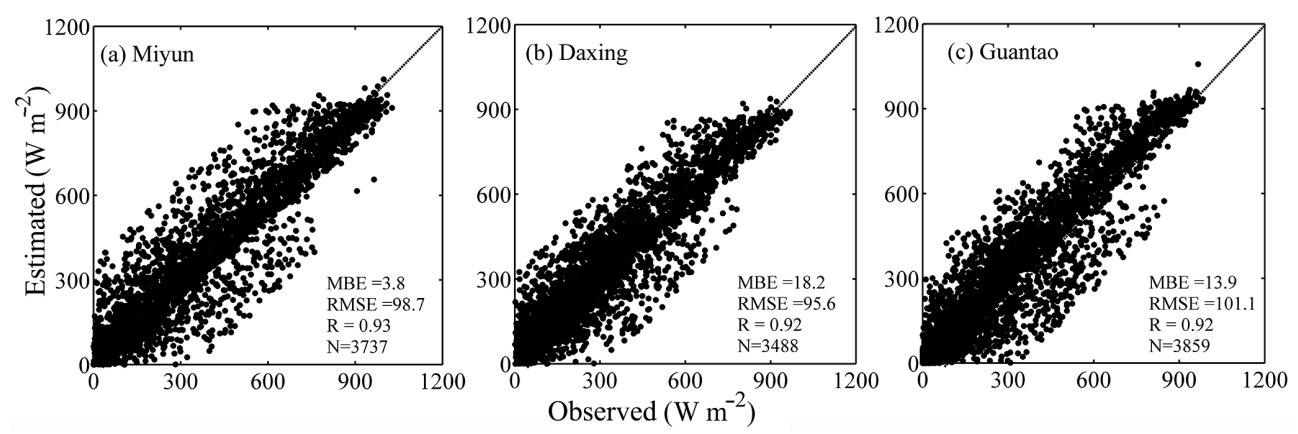

Figure 7. Comparison between the observed and the estimated hourly SSR at three experimental stations over the Haihe River basin in 2009. Units of MBE and RMSE are $\mathrm{W} \mathrm{m}^{-2}$. Points outside $3 \sigma$ were removed (about $1.88 \%$ ).
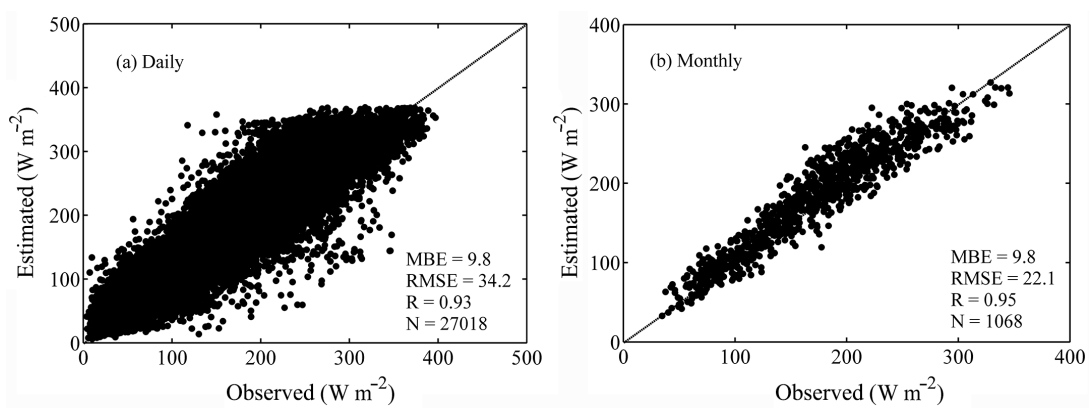

Figure 8. (a) Comparison between the observed and the estimated daily SSR at all CMA radiation stations in 2009. (b) Similar to panel (a), but for monthly SSR. Units of MBE and RMSE are $\mathrm{W} \mathrm{m}^{-2}$.

between satellite retrievals and ground observations at the hourly timescale.

\subsection{Validation of daily and monthly SSR at CMA}

Figure 8 shows the validation results for the daily and monthly mean SSR estimates at all CMA radiation stations, respectively. The daily and monthly mean SSR estimates show high correlation with the ground SSR measurements, with correlation coefficients of 0.93 and 0.95 , respectively. Both the daily and monthly mean SSR estimates exhibit a positive mean bias of $9.8 \mathrm{~W} \mathrm{~m}^{-2}$ (or $5.4 \%$ ) and RMSE of $34.2 \mathrm{~W} \mathrm{~m}^{-2}$ (or $19.1 \%$ ) on a daily scale, and $22.1 \mathrm{~W} \mathrm{~m}^{-2}$ (or $12.3 \%$ ) on a monthly scale. These RMSE values are comparable to the results of Kawai and Kawamura (2005) with $19.5 \%$ daily RMSE, those of $\mathrm{Lu}$ et al. (2010) with $17.7 \%$ daily RMSE, and the results of Lu et al. (2011) with $20.4 \%$ daily RMSE and $11.4 \%$ monthly RMSE. Moreover, the daily mean RMSE of our study is obviously lower than that of Jia et al. (2013), who estimate SSR with FY-2C and find a daily mean RMSE over China of about $49.3 \mathrm{~W} \mathrm{~m}^{-2}$ (or $27.5 \%$ ). These results suggest that our SSR estimation with MTSAT data works well for various climate regions, land cover types, and elevations. The differences between satellite-derived estimates and ground observations may be attributed to calibration uncertainty of the satellite sensor, the cloud detection error, uncertainty in the retrieval algorithm, errors in ground observations, and the representativeness of the station data. The representativeness of the station data is crucial for evaluating the satellite-derived estimates. For example, the Emeishan station (no. 56385) of CMA was deployed at the top of Mt. Emei, and the station cannot represent the corresponding pixel of MTSAT well. The mean elevation of the pixel is $1005 \mathrm{~m}$, while the station's elevation is $3047 \mathrm{~m}$.

The spatial distribution of MBE and RMSE for daily and monthly mean SSR estimates at all the CMA radiation stations is presented in Fig. 9. Most of the daily and monthly mean MBE values are positive and less than $30 \mathrm{~W} \mathrm{~m}^{-2}$. The large positive MBE mainly located in southern China, in which the corresponding RMSE values are relatively large. This phenomenon can be easily explained, because southern China $\left(20-35^{\circ} \mathrm{N}, 103-120^{\circ} \mathrm{E}\right)$ is the largest cloudy subtropical continental region in China (Yu et al., 2001), which was also confirmed by Li et al. (2004) based on multi-year ISCCP data and surface cloud observations. If cloud distribution becomes more complicated, the accuracy of cloud parameters estimates (see Sect. 3.3) will decrease, leading to larger error in SSR retrieval. However, most of the RMSEs are less than $40 \mathrm{~W} \mathrm{~m}^{-2}$ for daily SSR and less than $30 \mathrm{~W} \mathrm{~m}^{-2}$ for monthly mean SSR, indicating the retrieval algorithm had relatively reliable estimation performance at individual observation stations. 

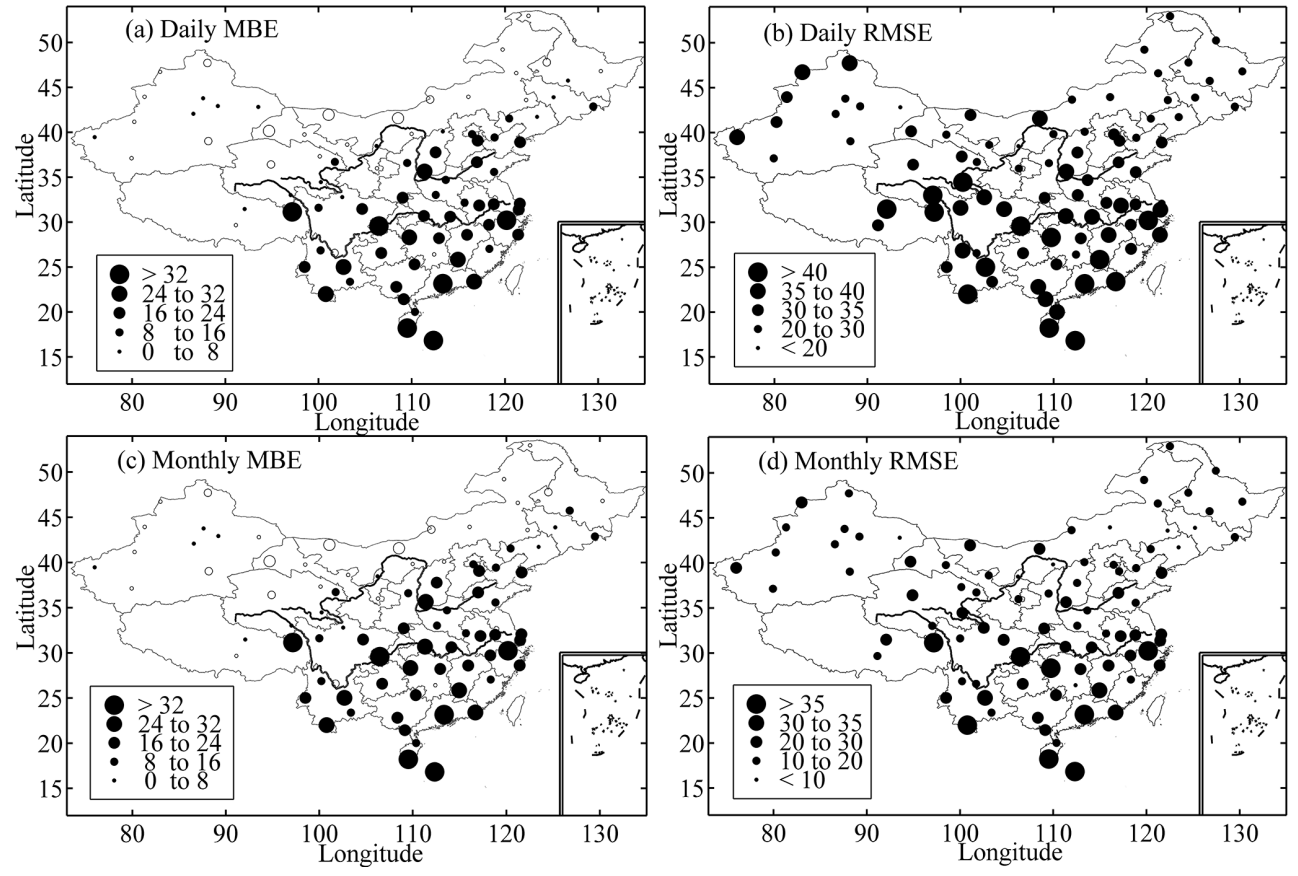

Figure 9. Spatial distributions of MBE and RMSE for daily $(\mathbf{a}, \mathbf{b})$ and monthly $(\mathbf{c}, \mathbf{d})$ SSR estimates at all CMA radiation stations in 2009. The size of the circles corresponds to the MBE and RMSE values. The solid circle means that the MBE is greater than zero, and the open circle means that the MBE is less than zero. The units of RMSE and MBE described on the legend are in $\mathrm{W} \mathrm{m}^{-2}$.
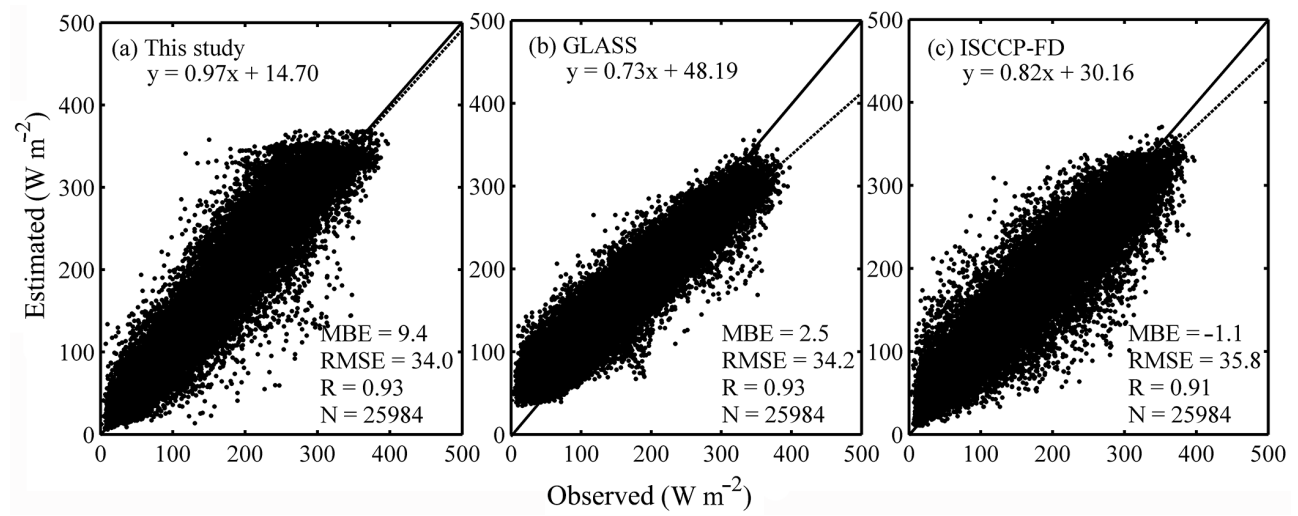

Figure 10. Comparison between the observed and the estimated daily SSR at all CMA radiation stations in 2009 for (a) this study, (b) GLASS, and (c) ISCCP-FD. Units of MBE and RMSE are $\mathrm{W} \mathrm{m}^{-2}$.

\subsection{Comparisons with other SSR estimates}

Two products of satellite retrieval SSR are selected to compare with the SSR estimate in this study. One is the Global Land Surface Satellite (GLASS) SSR product, which was also retrieved from MTSAT data by look-up table method (Zhang et al., 2014). The GLASS SSR algorithm is similar to the photosynthetically active radiation (PAR) retrieval algorithm of Liang et al. (2006). The other is the ISCCP-FD SSR product, which was produced by a NASA Goddard Institute for Space Studies (GISS) radiative transfer model based on the ISCCP D1 data at $2.5^{\circ}$ spatial resolution and $3 \mathrm{~h}$ tempo- ral resolution (Zhang et al., 2004). It may incur large errors to validate ISCCP-FD SSR products by using instantaneous in situ measurements because its spatial resolution is rather coarse (about $280 \mathrm{~km}$ ). However, at daily timescale, the spatial sampling errors become small (Li et al., 2005). Thus, we compare our SSR estimates with GLASS and ISCCPFD product at a daily timescale. Figure 10 shows the performance comparisons between our SSR estimates and the two satellites' SSR products on a daily timescale at all CMA radiation stations except the Emeishan station during 2009. The number of daily validation data here is less than in Fig. 7a due to some missing values in the GLASS products at some 

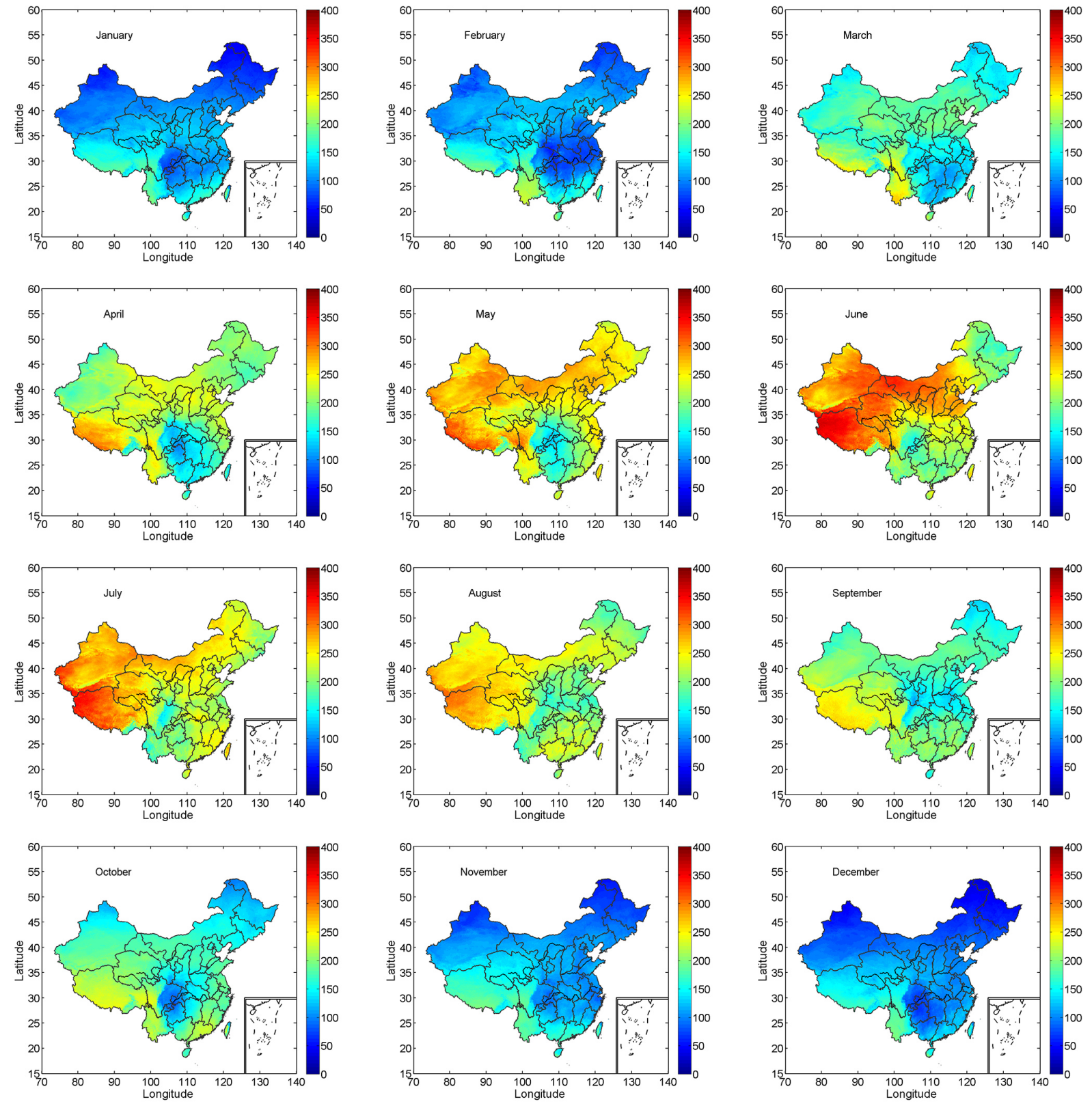

Figure 11. SSR estimates for 12 months in 2009 over mainland China. The unit of the SSR is $\mathrm{W} \mathrm{m}^{-2}$, and the pixel size is about $5 \mathrm{~km}$.

points, which are excluded from comparison. As shown in the Fig. 10, the ISCCP-FD SSR retrievals perform slightly worse than the ones of our algorithm and GLASS in terms of RMSE and $R$. The RMSE of our algorithm is comparable to the one of GLASS, though the MBE of our algorithm is larger than the one of GLASS. GLASS produces smaller scattering than our algorithm, while it underestimates the SSR at peak values and overestimates the SSR at low values. This would be due to the coarse spectral resolution of geostationary satellites (MTSAT), which cannot work well in the extreme conditions (namely, extremely low value and high values). Another feature is that our algorithm generally overestimates the SSR, with mean MBE of $9.4 \mathrm{~W} \mathrm{~m}^{-2}$. This phenomenon may be attributed to the general underestimations of liquid water path and ice water path, which can be seen in Figs. 3 and 4. We suspect that the general underestimations of liquid water path and ice water path in Figs. 3 and 4 would also stem from the coarse spectral resolution of MTSAT. However, the linear fitting curve of our estimate is closer to the $1: 1$ line than the ones of GLASS and ISCCPFD. This demonstrates that our algorithm can produce a comparable or even higher accuracy than the GLASS and the ISCCP-FD products. 


\subsection{Applications in China}

Based on the above SSR retrieval scheme and MTSAT data, we derive an 8-year high-spatiotemporal-resolution SSR data set (hourly, 5km) over China from 2007 to 2014. This data set is significantly important for the regions where few ground-based measurements are available, such as the Tibetan Plateau. Figure 11 shows the monthly mean SSR images for 12 months in 2009 over mainland China. As can be seen, these 12 images thoroughly exhibit the spatiotemporal patterns of SSR over mainland China. The spatial distribution characteristics of Fig. 11 are consistent with the result of Tang et al. (2013), which was derived based on the SSR estimations at 716 CMA stations. The SSR values are the highest in summer and lowest in winter, and spring and autumn are in the middle. The formation of this phenomenon is primarily controlled by sun elevation and the annual cycle of day length. In addition, some interesting regional characteristics can be found. The maximum radiation appears over the Tibetan Plateau, where the average elevation is more than $4 \mathrm{~km}$ and thus radiation extinction is small. The minimum radiation is over southwestern China (Sichuan Basin and Guizhou), which is often covered by stratiform clouds. At the same time, both of the two extreme values lie on the belt between 25 and $35^{\circ} \mathrm{N}$. SSR generally increases from east to west except for southwestern China, and decreases with increasing latitude in western China. There is no doubt that the sparse ground-based observations could not distinguish such regional differences in SSR distribution. The 8-year SSR data set is available via http://www.tpedatabase.cn/.

\section{Conclusions and remarks}

To obtain high-resolution SSR data, this study developed an ANN-based algorithm to estimate cloud parameters (cloud mask, effective particle radius, and liquid/ice water path) from MTSAT imagery. The algorithm was built by the combination of MODIS cloud products and MTSAT data. The estimated cloud parameters and other information (such as aerosol, ozone, $\mathrm{PW}$ ) were put into a parameterization model to estimate SSR. The estimated SSR was validated against both experimental data and operational station data in China, with an RMSE of $98.5 \mathrm{~W} \mathrm{~m}^{-2}$ for hourly SSR, $34.2 \mathrm{~W} \mathrm{~m}^{-2}$ for daily SSR, and $22.1 \mathrm{~W} \mathrm{~m}^{-2}$ for monthly SSR, as well as an MBE of about $10 \mathrm{~W} \mathrm{~m}^{-2}$.

Compared with two satellite radiation products (GLASS and ISCCP-FD), the SSR estimate presented in this study has comparable accuracy in terms of RMSE. GLASS underestimates the peak values of SSR, while it overestimates the low values. Our algorithm generally overestimates the SSR, which might be attributed to the underestimation of the cloud water path. The combining of CLOUDSAT and MTSAT in the future may be an alternative method to further improve the accuracy of cloud parameters, because CLOUDSAT has a greater advantage in retrieving cloud parameters than MODIS. 


\section{Appendix A}

\section{A1 Cloud parameterization}

The cloud parameterization schemes of Chou and Suarez (1999) are actually parameterization of three key parameters, i.e., optical thickness, single-scattering co-albedo, and asymmetry factor, for ice/water cloud at 11 individual broad spectral bands. They are expressed as

$\delta=\operatorname{CWP}\left(a_{0}+a_{1} / r_{\mathrm{e}}\right)$,

$1-\omega=b_{0}+b_{1} r_{\mathrm{e}}+b_{2} r_{\mathrm{e}}^{2}$,

$g=c_{0}+c_{1} r_{\mathrm{e}}+c_{2} r_{\mathrm{e}}^{2}$,

where $a, b$, and $c$ are regression coefficients and their values are given in Chou and Suarez (1999). $r_{\mathrm{e}}$ is the effective particle radius for ice/water cloud, and CWP is the cloud ice/water path. Taking the ratio of the extraterrestrial solar radiation of each band to that of the total spectrum for weight, the singlescattering properties for ice/water cloud at shortwave broadband can be derived.

$\bar{\delta}=-\log \left(\frac{\sum_{i=1}^{11} S_{0 i} \cdot e^{\left(-\delta_{\mathrm{i}}\right)}}{\sum_{i=1}^{11} S_{0 i}}\right)$,

$\bar{\omega}=-\log \left(\frac{\sum_{i=1}^{11} S_{0 i} \cdot e^{\left(-\delta_{\mathrm{i}} \cdot \omega_{\mathrm{i}}\right)}}{\sum_{i=1}^{11} S_{0 i}}\right) / \bar{\delta}$,

$\left.\bar{g}=-\log \left(\frac{\sum_{i=1}^{11} S_{0 i} \cdot e^{\left(-\delta_{\mathrm{i}} \cdot \omega_{\mathrm{i}} \cdot g_{\mathrm{i}}\right)}}{\sum_{i=1}^{11} S_{0 i}}\right) / \bar{\delta} \cdot \bar{\omega}\right)$,

where $\delta_{\mathrm{i}}, \omega_{\mathrm{i}}$, and $g_{\mathrm{i}}$ are the single-scattering properties for ice/water cloud at each band, $S_{0 i}$ is the extraterrestrial solar radiation of each band.

Therefore, if the values of CWP and $r_{\mathrm{e}}$ were known, the single-scattering properties at shortwave broadband can be determined. Furthermore, the transmittance due to water cloud attenuation $\left(\bar{\tau}_{\mathrm{wc}}\right)$ and ice cloud attenuation $\left(\bar{\tau}_{\mathrm{ic}}\right)$ can be obtained as follows:

$\bar{\tau}_{\mathrm{wc}}=e^{\left(-\bar{\delta}_{\mathrm{w}} / \mu_{0}\right)}$,

$\bar{\tau}_{\text {ic }}=e^{\left(-\bar{\delta}_{i} / \mu_{0}\right)}$,

where $\mu_{0}$ is the cosine of solar zenith angle. $\bar{\tau}_{\mathrm{wc}}$ and $\bar{\tau}_{\text {ic }}$ can be divided into processes of scattering and absorption, re- spectively.

$\bar{\tau}_{\mathrm{wc}}=\bar{\tau}_{\mathrm{wca}} \bar{\tau}_{\mathrm{wcs}}$,

$\bar{\tau}_{\text {ic }}=\bar{\tau}_{\text {ica }} \bar{\tau}_{\text {ics }}$,

where $\bar{\tau}_{\text {wca }}$ and $\bar{\tau}_{\text {wcs }}$ are transmittances due to water cloud absorption and scattering, respectively; $\bar{\tau}_{\text {ica }}$ and $\bar{\tau}_{\text {ics }}$ are transmittances due to ice cloud absorption and scattering, respectively.

\section{A2 SSR parameterization}

SSR under cloudy-sky conditions can be given by the following equation, if not taking into account the multiple reflections between the ground and atmosphere,

$R_{\mathrm{sw}, \mathrm{cld}}=R_{0}\left(\bar{\tau}_{\mathrm{b}}+\bar{\tau}_{\mathrm{d}}\right)$,

where $R_{0}$ is solar radiation on a horizontal surface at the top of atmosphere, and $\bar{\tau}_{\mathrm{b}}$ and $\bar{\tau}_{\mathrm{d}}$ are the broadband direct radiative transmittance and the diffuse radiative transmittance, which are given by

$\bar{\tau}_{\mathrm{b}} \approx \bar{\tau}_{\mathrm{oz}} \bar{\tau}_{\mathrm{w}} \bar{\tau}_{\mathrm{g}} \bar{\tau}_{\mathrm{r}} \bar{\tau}_{\mathrm{a}} \bar{\tau}_{\mathrm{c}}$

$\bar{\tau}_{\mathrm{d}}=\bar{\tau}_{\mathrm{d} 1}+\bar{\tau}_{\mathrm{d} 2}+\bar{\tau}_{d 3}$

where $\bar{\tau}_{\mathrm{r}}, \bar{\tau}_{\mathrm{a}}, \bar{\tau}_{\mathrm{oz}}, \bar{\tau}_{\mathrm{w}}, \bar{\tau}_{\mathrm{g}}$, and $\bar{\tau}_{\mathrm{c}}$ are solar radiation transmittances of six damping processes in the atmospheric layer, viz. Rayleigh scattering, aerosol extinction, ozone absorption, water vapor absorption, permanent gas absorption, and cloud extinction, respectively. $\bar{\tau}_{\mathrm{a}}$ is divided into processes of scattering and absorption.

$\bar{\tau}_{\mathrm{a}}=\bar{\tau}_{\mathrm{aa}} \bar{\tau}_{\mathrm{as}}$,

where $\bar{\tau}_{\text {aa }}$ and $\bar{\tau}_{\text {as }}$ are transmittances due to the aerosol absorption and scattering, respectively. Detailed calculation of $\bar{\tau}_{\mathrm{r}}, \bar{\tau}_{\mathrm{a}}, \bar{\tau}_{\mathrm{oz}}, \bar{\tau}_{\mathrm{w}}$, and $\bar{\tau}_{\mathrm{g}}$ can be found in Yang et al. (2006). $\bar{\tau}_{\mathrm{c}}$ can be calculated according the above cloud parameterization scheme.

$\bar{\tau}_{\mathrm{d} 1}, \bar{\tau}_{\mathrm{d} 2}$, and $\bar{\tau}_{\mathrm{d} 3}$ are forward diffuse radiative transmittances due to Rayleigh scattering, aerosol scattering, and cloud scattering, and are given by

$\bar{\tau}_{\mathrm{d} 1} \approx 0.5 \bar{\tau}_{\mathrm{oz}} \bar{\tau}_{\mathrm{g}} \bar{\tau}_{\mathrm{w}} \bar{\tau}_{\mathrm{aa}} \bar{\tau}_{\mathrm{wca}}\left(1-\bar{\tau}_{\mathrm{r}}\right)$ for water cloud,

$\bar{\tau}_{\mathrm{d} 1} \approx 0.5 \bar{\tau}_{\mathrm{oz}} \bar{\tau}_{\mathrm{g}} \bar{\tau}_{\mathrm{w}} \bar{\tau}_{\mathrm{aa}} \bar{\tau}_{\mathrm{ica}}\left(1-\bar{\tau}_{\mathrm{r}}\right)$ for ice cloud,

$\bar{\tau}_{\mathrm{d} 2} \approx f_{\mathrm{a}}\left(\mu_{0}\right) \bar{\tau}_{\mathrm{oz}} \bar{\tau}_{\mathrm{g}} \bar{\tau}_{\mathrm{w}} \bar{\tau}_{\mathrm{aa}} \bar{\tau}_{\mathrm{wca}} \bar{\tau}_{\mathrm{r}}\left(1-\bar{\tau}_{\mathrm{as}}\right)$

for water cloud,

$\bar{\tau}_{\mathrm{d} 2} \approx f_{\mathrm{a}}\left(\mu_{0}\right) \bar{\tau}_{\mathrm{oz}} \bar{\tau}_{\mathrm{g}} \bar{\tau}_{\mathrm{w}} \bar{\tau}_{\mathrm{aa}} \bar{\tau}_{\mathrm{ica}} \bar{\tau}_{\mathrm{r}}\left(1-\bar{\tau}_{\mathrm{as}}\right)$

for ice cloud, 
$\bar{\tau}_{\mathrm{d} 3} \approx f_{\mathrm{w}}\left(\mu_{0}\right) \bar{\tau}_{\mathrm{oz}} \bar{\tau}_{\mathrm{g}} \bar{\tau}_{\mathrm{w}} \bar{\tau}_{\mathrm{aa}} \bar{\tau}_{\mathrm{wca}} \bar{\tau}_{\mathrm{r}} \bar{\tau}_{\mathrm{as}}\left(1-\bar{\tau}_{\mathrm{wcs}}\right)$

for water cloud,

$\bar{\tau}_{\mathrm{d} 3} \approx f_{\mathrm{i}}\left(\mu_{0}\right) \bar{\tau}_{\mathrm{oz}} \bar{\tau}_{\mathrm{g}} \bar{\tau}_{\mathrm{w}} \bar{\tau}_{\mathrm{aa}} \bar{\tau}_{\mathrm{ica}} \bar{\tau}_{\mathrm{r}} \bar{\tau}_{\mathrm{as}}\left(1-\bar{\tau}_{\mathrm{ics}}\right)$

for ice cloud,

where 0.5 is the fraction of the Rayleigh-scattered flux which is scattered into the lower hemisphere (another 0.5 is scattered upward). $f_{\mathrm{a}}\left(\mu_{0}\right)$ is the fraction of the aerosol-scattered flux which is scattered into the lower hemisphere $\left(1-f_{\mathrm{a}}\left(\mu_{0}\right)\right.$ is scattered upward), $f_{\mathrm{w}}\left(\mu_{0}\right)$ is the fraction of the water cloud-scattered flux which is scattered into the lower hemisphere $\left(1-f_{\mathrm{w}}\left(\mu_{0}\right)\right.$ is scattered upward $)$, and $f_{\mathrm{i}}\left(\mu_{0}\right)$ is the fraction of the ice cloud-scattered flux which is scattered into the lower hemisphere $\left(1-f_{\mathrm{i}}\left(\mu_{0}\right)\right.$ is scattered upward). The factors $f_{\mathrm{a}}\left(\mu_{0}\right), f_{\mathrm{w}}\left(\mu_{0}\right)$, and $f_{i}\left(\mu_{0}\right)$, which depend on cosine of the solar zenith angle $\left(\mu_{0}\right)$ and the asymmetry factor $(g)$ and can be derived by integration of scattering phase function, are given according to parameterization of Räisänen (2002) by

$$
\begin{aligned}
& f_{\mathrm{a}}\left(\mu_{0}\right)=0.4482+\left(5.3664-22.1608 t+28.6995 t^{2}\right. \\
& \left.-11.1348 t^{3}\right)\left(\frac{g_{\mathrm{a}}}{g_{\mathrm{a}}+1}\right), \\
& f_{\mathrm{w}}\left(\mu_{0}\right)=0.3312+1.1285\left(\mu_{0}^{0.7469}\right)\left(\frac{g_{\mathrm{w}}}{g_{\mathrm{w}}+1}\right), \\
& f_{\mathrm{i}}\left(\mu_{0}\right)=0.4250+0.9595\left(\mu_{0}^{0.8484}\right)\left(\frac{g_{\mathrm{i}}}{g_{\mathrm{i}}+1}\right),
\end{aligned}
$$

$t=\left(\mu_{0}+0.1\right)^{0.25}$

where, $g_{\mathrm{a}}, g_{\mathrm{w}}$, and $g_{\mathrm{i}}$ are the asymmetry factors of aerosol, water cloud, and ice cloud, respectively. The asymmetry factors of water cloud and ice cloud can be calculated according the above cloud parameterization. However, the asymmetry factors and single-scattering albedo of the aerosol are interpolated from the observed ones at all the AErosol RObotic NETwork (AERONET) sites (Dubovik and King, 2000).
Considering the multiple reflections between the ground and atmosphere, the SSR can be given by

$R_{\mathrm{sw}}=\frac{\left(1-C_{\mathrm{w}}-C_{\mathrm{i}}\right) R_{\mathrm{sw}, \mathrm{clr}}+C_{\mathrm{w}} R_{\mathrm{sw}, \mathrm{wc}}+C_{\mathrm{i}} R_{\mathrm{sw}, \mathrm{ic}}}{\left(1-\rho_{\mathrm{a}, \mathrm{all}} \rho_{\mathrm{g}}\right)}$,

where $R_{\mathrm{sw}}$ is SSR, $C_{\mathrm{w}}$, and $C_{\mathrm{i}}$ are water cloud cover and ice cloud cover, respectively. $R_{\mathrm{sw}, \mathrm{clr}}, R_{\mathrm{sw}, \mathrm{wc}}$, and $R_{\mathrm{sw}, \mathrm{ic}}$ are SSR under clear sky, water cloudy sky, and ice cloudy sky, respectively. $R_{\mathrm{sw}, \mathrm{clr}}$ can be derived from $R_{\mathrm{sw}, \mathrm{cld}}$ when $\bar{\tau}_{\mathrm{c}}, \bar{\tau}_{\text {wca }}, \bar{\tau}_{\text {ica }}$, $\bar{\tau}_{\mathrm{wcs}}$, and $\bar{\tau}_{\text {ics }}$ are all equal to $1 . \rho_{\mathrm{a} \text {,all }}$ and $\rho_{\mathrm{g}}$ are albedos of the atmosphere and ground, respectively. $\rho_{\mathrm{a} \text {,all }}$ can be determined by

$\rho_{\mathrm{a}, \mathrm{all}}=\left(1-C_{\mathrm{w}}-C_{i}\right) \rho_{\mathrm{a}, \mathrm{clr}}+C_{\mathrm{w}} \rho_{\mathrm{a}, \mathrm{wc}}+C_{i} \rho_{\mathrm{a}, \mathrm{ic}}$,

where $\rho_{\mathrm{a}, \mathrm{clr}}, \rho_{\mathrm{a}, \mathrm{wc}}$, and $\rho_{\mathrm{a}}$,ic are albedos of atmospheric under clear sky, water cloudy sky, and ice cloudy sky, respectively. They are given by

$$
\begin{aligned}
& \rho_{\mathrm{a}, \mathrm{clr}} \approx \bar{\tau}_{\mathrm{g}}^{\prime} \bar{\tau}_{\mathrm{w}}^{\prime} \bar{\tau}_{\mathrm{oz}}^{\prime} \bar{\tau}_{\mathrm{aa}}^{\prime}\left\{0.5\left(1-\bar{\tau}_{\mathrm{r}}^{\prime}\right)\right. \\
& \left.+\left[1-f_{\mathrm{a}}(1 / \sqrt{3})\right] \bar{\tau}_{\mathrm{r}}^{\prime}\left(1-\bar{\tau}_{\mathrm{as}}^{\prime}\right)\right\} \text { for clear skies, } \\
& \rho_{\mathrm{a}, \mathrm{wc}} \approx \bar{\tau}_{\mathrm{g}}^{\prime} \bar{\tau}_{\mathrm{w}}^{\prime} \bar{\tau}_{\mathrm{oz}}^{\prime} \bar{\tau}_{\mathrm{aa}}^{\prime} \bar{\tau}_{\mathrm{wca}}^{\prime}\left\{0.5\left(1-\bar{\tau}_{\mathrm{r}}^{\prime}\right)\right. \\
& +\left[1-f_{\mathrm{a}}(1 / \sqrt{3})\right] \bar{\tau}_{\mathrm{r}}^{\prime}\left(1-\bar{\tau}_{\mathrm{as}}^{\prime}\right) \\
& \left.+\left[1-f_{\mathrm{w}}(1 / \sqrt{3})\right] \bar{\tau}_{\mathrm{r}}^{\prime} \bar{\tau}_{\mathrm{as}}^{\prime}\left(1-\bar{\tau}_{\mathrm{wcs}}^{\prime}\right)\right\}
\end{aligned}
$$

for water cloud,

$$
\begin{aligned}
& \rho_{\mathrm{a}, \mathrm{ic}} \approx \bar{\tau}_{\mathrm{g}}^{\prime} \bar{\tau}_{\mathrm{w}}^{\prime} \bar{\tau}_{\mathrm{oz}}^{\prime} \bar{\tau}_{\mathrm{aa}}^{\prime} \bar{\tau}_{\mathrm{ica}}^{\prime}\left\{0.5\left(1-\bar{\tau}_{\mathrm{r}}^{\prime}\right)\right. \\
& \quad+\left[1-f_{\mathrm{a}}(1 / \sqrt{3})\right] \bar{\tau}_{\mathrm{r}}^{\prime}\left(1-\bar{\tau}_{\mathrm{as}}^{\prime}\right) \\
& \left.\quad+\left[1-f_{\mathrm{i}}(1 / \sqrt{3})\right] \bar{\tau}_{\mathrm{r}}^{\prime} \bar{\tau}_{\mathrm{as}}^{\prime}\left(1-\bar{\tau}_{\mathrm{ics}}^{\prime}\right)\right\} \text { for ice cloud }
\end{aligned}
$$

where the transmissivities $\bar{\tau}_{\mathrm{g}}^{\prime}, \bar{\tau}_{\mathrm{w}}^{\prime}, \bar{\tau}_{\mathrm{oz}}^{\prime}, \bar{\tau}_{\mathrm{r}}^{\prime}, \bar{\tau}_{\mathrm{aa}}^{\prime}, \bar{\tau}_{\mathrm{as}}^{\prime}, \bar{\tau}_{\text {wca }}^{\prime}, \bar{\tau}_{\text {ica }}^{\prime}$, $\bar{\tau}_{\text {wcs }}^{\prime}$, and $\bar{\tau}_{\text {ics }}^{\prime}$ are all evaluated at an effective relative air mass of $\sqrt{3}$ to account for absorption or reflectance over path lengths averaged over the whole upper hemisphere. 
Acknowledgements. This work was supported by the National Natural Science Foundation of China (grant no. 41301359), the "Strategic Priority Research Program (B)" of the Chinese Academy of Sciences (grant no. XDB03030306), the National Natural Science Foundation of China (grant no. 41190083; 41325019), and the Open Fund from the State Key Laboratory of Remote Sensing Science (grant OFSLRSS201303), which is cosponsored by the Institute of Remote Sensing and Digital Earth, Chinese Academy of Sciences, and Beijing Normal University. CMA radiation data were obtained from the National Meteorological Information Center. MTSAT data are available via http://weather.is.kochi-u.ac.jp/sat/GAME/. MODIS data are available via http://reverb.echo.nasa.gov/reverb/. BSRN radiation data are available via http://www.bsrn.awi.de. GLASS radiation data are available via http://glass-product.bnu.edu.cn/. ISCCP-FD radiation data are available via http://isccp.giss.nasa.gov.

Edited by: J. Huang

\section{References}

Benghanem, M. and Mellit, A.: Radial basis function networkbased prediction of global solar radiation data: application for sizing of a stand-alone photovoltaic system at Al-Madinah, Saudi Arabia, Energy, 35, 3751-3762, 2010.

Berbery, E. H., Mitchell, K. E., Benjamin, S., Smirnova, T., Ritchie, H., Hogue, R., and Radeva, E.: Assessment of land-surface energy budgets from regional and global models, J. Geophys. Res., 104, 19329-19348, 1999.

Chesters, D., Robinson, W. D., and Uccellini, L. W.: Optimized retrievals of precipitable water from the VAS "Split Windows", J. Clim. Appl. Meteorol., 26, 10591066, doi:10.1175/15200450(1987)026<1059:OROPWF>2.0.CO;2, 1987.

Chou, M.-D. and Suarez, M. J.: A Solar Radiation Parameterization for Atmospheric Studies, NASA Tech. Rep. Ser. Global Model. Data Assimilation, Vol. 15, NASA Tech. Memo., TM1999-104606, Maryland, USA, 42 pp., 1999.

Deneke, H., Feijt, A., and Roebeling, R.: Estimating surface solar irradiance from METEOSAT SEVIRI-derived cloud properties, Remote Sens. Environ., 112, 3131-3141, doi:10.1016/j.rse.2008.03.012, 2008.

Deneke, H. M., Knap, W. H., and Simmer C.: Multiresolution analysis of the temporal variance and correlation of transmittance and reflectance of an atmospheric column, J. Geophys. Res., 114, D17206, doi:10.1029/2008JD011680, 2009.

Dubovik, O. and King, M. D.: A flexible inversion algorithm for retrieval of aerosol optical properties from Sun and sky radiance measurements, J. Geophys. Res., 105, 20673-20696, 2000.

Hammer, A., Heinemann, D., Hoyer, C., Lorenz, E., Muller, R., and Beyer, H. G.: Solar energy assessment using remote sensing technologies, Remote Sens. Environ., 86, 423-432, doi:10.1016/S0034-4257(03)00083-X, 2003.

Halthore, R. N., Crisp, D., Schwartz, S. E., Anderson, G. P., Berk, A., Bonnel, B., Boucher, O., Chang, F.-L., Chou, M.-D., Clothiaux, E. E., Dubuisson, P., Fomin, B., Fouquart, Y., Freidenreich, S., Gautier, C., Kato, S., Laszlo, I., Li, Z., Mather, J. H., Plana-Fattori, A., Ramaswamy, V., Ricchiazzi, P., Shiren, Y., Trishchenko, A., and Wiscombe, W.: Intercomparison of shortwave radiative transfer codes and measurements, J. Geophys. Res., 110, D11206, doi:10.1029/2004JD005293, 2005.

Hess, M., Koepke, P., and Schult, I.: Optical properties of aerosol and clouds: the software package OPAC, B. Am. Meteorol. Soc., 79, 831-844, 1998.

Huang, G., Ma, M., Liang, S., Liu, S., and Li, X.: A LUTbased approach to estimate surface solar irradiance by combining MODIS and MTSAT data, J. Geophys. Res., 116, D22201, doi:10.1029/2011JD016120, 2011.

Huang G., Liu S., and Liang S.: Estimation of net surface shortwave radiation from MODIS data, Int. J. Remote Sens., 33, 804-825, 2012.

Huang, J., Minnis, P., Lin, B., Yi, Y., Khaiyer, M., Arduini, R., Fan, A., and Mace, G.: Advanced retrievals of multilayered cloud properties using multispectral measurements, J. Geophys. Res., 110, D15S18, doi:10.1029/2004JD005101, 2005.

Huang, J., Minnis, P., Lin, B., Yi, Y., Sun-Mack, S., Fan, T., and Ayers, J.: Determination of ice water path in ice-over-water cloud systems using combined MODIS and AMSR-E measurements, Geophys. Res. Lett., 33, L21801, doi:10.1029/2006GL027038, 2006.

Huang, J., Yu, H., Guan, X., Wang, G., and Guo, R.: Accelerated dryland expansion under climate change, Nature Climate Change, 6, 166-171, doi:10.1038/nclimate2837, 2016.

Jia, B., Xie, Z., Dai, A., Shi, C., and Chen F.: Evaluation of satellite and reanalysis products of downward surface solar radiation over East Asia: Spatial and seasonal variations, J. Geophys. Res.Atmos., 118, 3431-3446, doi:10.1002/jgrd.50353, 2013.

Kawai, Y. and Kawamura H.: Validation and improvement of satellite derived surface solar radiation over the northwestern Pacific Ocean, J. Oceanogr., 61, 79-89, doi:10.1007/s10872-005-00217, 2005.

Kim, D. and Ramanathan, V.: Solar radiation budget and radiative forcing due to aerosols and clouds, J. Geophys. Res., 113, D02203, doi:10.1029/2007JD008434, 2008.

King, M., Menzel, W. P., Kaufman, Y. J., Tanre, D., Gao, B., Platnick, S., Ackerman, S. A., Remer, L. A., Pincus, R., Hubanks, P. $\mathrm{K}$. : Cloud and aerosol properties, precipitable water, and profiles of temperature and water vapor from MODIS, IEEE T. Geosci Remote, 41, 442-458, doi:10.1109/TGRS.2002.808226, 2003.

King, M. D., Tsay, S. C., Platnick, S. E., Wang, M. H., and Liou, K. N.: Cloud retrieval algorithms for MODIS: optical thickness, effective particle radius, and thermodynamic phase, MODIS Algorithm Theoretical Basis Document No. ATBD-MOD-05, 1997.

Koepke, P., Hess, M., Schult, I., and Shettle, E. P.: Global Aerosol Data Set, Report No. 243, Max-Planck Institut für Meteorologie, Hamburg, Germany, 1997.

Li, Y. Y., Yu, R. C., Xu, Y. P., and Zhang, X. H.: Spatial distribution and seasonal variation of cloud over China based on ISCCP data and surface observations, J. Meteorol. Soc. Jpn., 82, 761-773, 2004.

Li, Z., Cribb, M., Chang, F. L., Trishchenko, A., and Luo, Y.: Natural variability and sampling errors in solar radiation measurements for model validation over the atmospheric radiation measurement Southern Great Plains region, J. Geophys. Res., 110, D15S19, doi:10.1029/2004JD005028, 2005.

Liang, S., Zheng, T., Liu, R. G., Fang, H. L., Tsay, S. C., and Running S.: Estimation of incident photosynthetically active radia- 
tion from Moderate Resolution Imaging Spectrometer data, J. Geophys. Res., 111, D15208, doi:10.1029/2005JD006730, 2006.

Liu, S. M., Xu, Z., Zhu, Z., Jia, Z., and Zhu, M.: Measurements of evapotranspiration from eddy-covariance systems and large aperture scintillometers in the Hai River Basin, China, J. Hydrol., 487, 24-38 doi:10.1016/j.jhydrol.2013.02.025, 2013.

Liu, Y., Xia, J., Shi, C.-X., and Hong, Y.: An Improved Cloud Classification Algorithm for China's FY-2C Multi-Channel Images Using Artificial Neural Network, Sensors, 9, 5558-5579, 2009.

Lu, N., Liu, R., Liu, J., and Liang, S.: An algorithm for estimating downward shortwave radiation from GMS 5 visible imagery and its evaluation over China, J. Geophys. Res., 115, D18102, doi:10.1029/2009JD013457, 2010.

Lu, N., Qin, J., Yang, K., and Sun, J.: A simple and e_cient algorithm to estimate daily global solar radiation from geostationary satellite data, Energy, 36, 3179-3188, doi:10.1016/j.energy.2011.03.007, 2011.

Ma, Y. and Pinker, R. T.: Modeling shortwave radiative fluxes from satellites, J. Geophys. Res., 117, D23202, doi:10.1029/2012JD018332, 2012.

Minnis, P., Huang, J., Lin, B., Yi, Y., Arduini, R., Fan, T., Ayers, J., and Mace, G.: Ice cloud properties in ice-over-water cloud systems using Tropical Rainfall Measuring Mission (TRMM) visible and infrared scanner and TRMM Microwave Imager data, J. Geophys. Res., 112, D06206, doi:10.1029/2006JD007626, 2007.

Mondol, J. D., Yohanis, Y. G., and Norton, B.: Solar radiation modelling for the simulation of photovoltaic systems, Renew. Energ., 33, 1109-1120, 2008.

Mueller, R., Matsoukas, C., Gratzki, A., Behr, H., and Hollmann, R.: The CM-SAF operational scheme for the satellite based retrieval of solar surface irradiance-A LUT based eigenvector hybrid approach, Remote Sens. Environ., 113, 1012-1024, doi:10.1016/j.rse.2009.01.012, 2009.

Oliver, M. and Jackson, T.: Energy and economic evaluation of building-integrated photovoltaics, Energy, 26, 431-439, 2001.

Pinker, R. T., Tarpley, J. D., Laszlo, I., Mitchell, K. E., Houser, P. R., Wood, E. F., Schaake, J. C., Robock, A., Lohmann, D., Cosgrove, B. A., Sheffield, J., Duan, Q., Luo, L., and Higgins, R. W.: Surface radiation budgets in support of the GEWEX ContinentalScale International Project (GCIP) and the GEWEX Americas Prediction Project (GAPP), including the North American Land Data Assimilation System (NLDAS) project, J. Geophys. Res., 108, 8844, doi:10.1029/2002JD003301, 2003.

Posselt, R., Mueller, R., Stöckli, R., and Trentmann, J.: Remote sensing of solar surface radiation for climate monitoring-The CM-SAF retrieval in international comparison, Remote Sens. Environ., 118, 186-198, 2012.

Qin, J., Tang W. J., Yang, K., Lu N., Niu X. L., and Liang, S. L.: An efficient physically-based parameterization to derive surface solar irradiance based on satellite atmospheric products, J. Geophys. Res.-Atmos., 120, 4975-4988, doi:10.1002/2015JD023097, 2015.

Räisänen, P.: Two-stream approximations revisited: A new improvement and tests with GCM data, Q. J. Roy. Meteor. Soc., 128, 2397-2416, doi:10.1256/qj.01.161, 2002.

Rigollier, C., Lefèvre, M., and Wald, L.: The method Heliosat-2 for deriving shortwave solar radiation from satellite images, Sol. Energy, 77, 159-169, doi:10.1016/j.solener.2004.04.017, 2004.
Roebeling, R., van Putten, E., Genovese, G., and Rosema, A.: Application of meteosat derived meteorological information for crop yield predictions in Europe, Int. J. Remote Sens., 25, 53895401, 2004.

Schaaf, C. B., Gao, F., Strahler, A. H., Lucht, W., Li, X., Tsang, T., and Roy, D.: First operational BRDF, albedo nadir reflectance products from MODIS, Remote Sens. Environ., 83, 135-148, doi:10.1016/S0034-4257(02)00091-3, 2002.

Stackhouse, P. W., Gupta, S. K., Cox, S. J., Mikovitz, J. C., Zhang, T., and Chiacchio, M.: 12-year surface radiation budget data set, GEWEX News, 14, 10-12, 2004.

Sun, Z., Liu, J., Zeng, X., and Liang H.: Parameterization of instantaneous global horizontal irradiance: Cloudy-sky component, J. Geophys. Res., 117, D14202, doi:10.1029/2012JD017557, 2012.

Tanahashi, S., Kawamura, H., Matsuura, T., Takahashi, T., and Yusa H.: A system to distribute satellite incident solar radiation in realtime, Remote Sens. Environ., 75, 412-422, doi:10.1016/S00344257(00)00183-8, 2001.

Tang, W. J., Yang, K., He, J., and Qin, J.: Quality control and estimation of global solar radiation in China, Sol. Energy, 84, 466-475, 2010.

Tang, W. J., Yang, K., Qin, J., and Min, M.: Development of a 50year daily surface solar radiation dataset over China, Sci. China Ser. D, 56, 1555-1565, doi:10.1007/s11430-012-4542-9, 2013.

Wang, H. M. and Pinker, R. T.: Shortwave radiative fluxes from MODIS: Model development and implementation, J. Geophys. Res., 114, D20201, doi:10.1029/2008JD010442, 2009.

Wang, P., Stammes, P., and Mueller, R.: Surface solar irradiance from SCIAMACHY measurements: algorithm and validation, Atmos. Meas. Tech., 4, 875-891, doi:10.5194/amt-4-875-2011, 2011.

Wang, P., Sneep, M., Veefkind, J. P., Stammes, P., and Levelt, P. F.: Evaluation of broadband Surface solar irradiance from the Ozone Monitoring Instrument, Remote Sens. Environ., 149, 88 99, doi:10.1016/j.rse.2014.03.036, 2014.

Wu, F. T. and Fu, C. B.: Assessment of GEWEX/SRB version 3.0 monthly global radiation dataset over China, Meteorol. Atmos. Phys., 112, 155-166, 2011.

Xue, B. L., Wang, L., Li, X., Yang, K., Chen, D., and Sun, L.: Evaluation of evapotranspiration estimates for two river basins on the Tibetan Plateau by a water balance method, J. Hydrol., 492, 290297, doi:10.1016/j.jhydrol.2013.04.005, 2013.

Yang, K., Koike, T., and Ye, B.: Improving estimation of hourly, daily, and monthly solar radiation by importing global data sets, Agr. Forest Meteorol., 137, 43-55, 2006.

Yang, K., Pinker, R. T., Ma, Y., Koike, T., Wonsick, M. M., Cox, S. J., Zhang, Y., and Stackhouse P.: Evaluation of satellite estimates of downward shortwave radiation over the Tibetan Plateau, J. Geophys. Res., 113, D17204, doi:10.1029/2007JD009736, 2008.

Yeom, J. M. and Han, K. S.: Improved estimation of surface solar insolation using a neural network and MTSAT-1R data, Comput. Geosci., 36, 590-597, 2010.

Yeom, J. M., Han, K. S., Kim, Y. S., and Jang, J. D.: Neural network determination of cloud attenuation to estimate insolation using MTSAT-1R data, Int. J. Remote Sens., 29, 6193-6208, 2008.

Yu, R. C., Yu, Y. Q., and Zhang, M. H.: Comparing cloud radiative properties between the eastern China and the Indian monsoon region, Adv. Atmos. Sci., 18, 1090-1102, 2001. 
Zhang, X. T., Liang, S. L., Zhou, G. Q., Wu, H. R., and Zhao, X.: Generating Global LAnd Surface Satellite incident shortwave radiation and photosynthetically active radiation products from multiple satellite data, Remote Sens. Environ., 152, 318-332, 2014.
Zhang, Y., Rossow, W. B., Lacis, A. A., Oinas, V., and Mishchenko, M. I.: Calculation of radiative fluxes from the surface to top of atmosphere based on ISCCP and other global data sets-refinements of the radiative transfer model and the input data, J. Geophys. Res., 109, D19105, doi:10.1029/2003JD004457, 2004. 